\title{
Immunoglobulin response to intravenous streptokinase in acute myocardial infarction
}

\author{
Mary Lynch, W A Littler, B L Pentecost, R A Stockley
}

\begin{abstract}
Objective-To devise assays to assess and follow the specific antibody response in patients treated with streptokinase for acute myocardial infarction.
\end{abstract}

Design-Venous blood samples were collected before treatment with streptokinase started and subsequently at regular intervals over one year. Specific IgG and subclass IgG1 were assessed by an enzyme linked immunosorbent assay.

Setting-Coronary care unit in a general hospital.

Patients-48 patients with acute myocardial infarction: 22 patients had venous blood samples taken at presentation only; serial blood samples were taken from 20 patients who then received thrombolytic therapy with streptokinase and six patients who were unsuitable for thrombolytic therapy.

Results-Titres of antibodies to streptokinase were low at presentation in 36 $(75 \%)$ of the 48 patients. Serial measurements made in 20 patients showed the virtual disappearance of antibody within the first 24 hours. This was followed by a steady increase in the specific IgG1 titre, which peaked at day 14 before gradually declining. Values at one year remained significantly higher than baseline values. There was no evidence of an IgM response in the patients studied.

Conclusion-Low titres of antibodies to streptokinase were widespread in the population. Antibody was consumed after treatment and the subsequent immunoglobulin rise suggested a secondary immune response; the recently described neutralising capacity to streptokinase is probably related to this antibody.

Thrombolysis is now a routine treatment for acute myocardial infarction. It improves morbidity by reducing infarct size and reduces overall mortality. ${ }^{12}$ Streptokinase is the most widely used and least expensive thrombolytic agent; in the United Kingdom more experience has been gained with this agent than with any other. It is most often produced by $\beta$ haemolytic streptococci group $C$ but is also produced by groups $\mathrm{A}, \mathrm{D}$, and E. Because streptokinase is a foreign protein it is antigenic, unlike some other thrombolytic agents such as tissue plasminogen activator or urokinase. Studies of the dose of streptokinase required to achieve a thrombolytic state showed that antibodies to streptokinase were widespread in the community. ${ }^{34}$ The presence of these antibodies raises the possibility of an adverse immune reaction after treatment with streptokinase.

There are few published reports on the allergic aspect of thrombolytic therapy with streptokinase and these are mainly anecdotal. The reported incidence of allergic reactions varies from $1.7 \%$ to $18 \% .^{5}$ These reactions include acute anaphylaxis, ${ }^{5}$ serum sickness, ${ }^{6-8}$ and delayed hypersensitivity. ${ }^{9}$ Nevertheless, the relation of the reactions to the immune response is poorly understood. Currently, it is recommended that streptokinase treatment should not be repeated between three days and six months after the initial dose.

The purpose of the present study was to devise assays to assess and follow the antibody response in patients given streptokinase for acute myocardial infarction so that the safety of streptokinase therapy can be determined more reliably.

\section{Patients and methods}

We studied 48 patients (38 men and 10 women, aged 42-80), with acute myocardial infarction. Myocardial infarction was diagnosed on the basis of chest pain and definite electrocardiographic changes (ST elevation $>2 \mathrm{~mm}$ or $\mathrm{T}$ wave inversion in both). Twenty two of the patients had a venous blood sample taken at presentation only. A further 20 patients who were suitable for thrombolytic therapy with streptokinase and six patients in whom streptokinase was contraindicated (duration of chest pain $>24$ hours, peptic ulceration, recent surgery etc) were followed for up to one year. For these 26 patients, $10 \mathrm{ml}$ of venous blood was taken at admission or immediately before treatment with streptokinase; within 24 hours of treatment or admission; on days $2-4$; days 7,14 , and 28 ; and then at intervals of approximately $2,4,6$, 8,10 months, and one year after treatment (samples were usually taken within seven days of each time point after one month).

Enzyme linked immunosorbent assays were developed for IgG and the IgG1 subclass by the methods of Voller et al. ${ }^{10}$ In brief, the wells of microtitre plates (Gibco, UK) were coated with $200 \mu \mathrm{l}$ of $300 \mathrm{IU} / \mathrm{ml}$ of streptokinase (Kabivitrum Pharmaceuticals) in 0.05 $\mathrm{mol} / \mathrm{l}$ carbonate/bicarbonate buffer ( $\mathrm{pH} 9.5$ ) and incubated for 16 hours at $4^{\circ} \mathrm{C}$. The plate was then washed three times in phosphate 
Figure 1 IgG standard curve (unbroken line) and IgG1 standard curve (dotted line) (1SD) $(n=6)$. The vertical axis is the optical density of the horizontal axis is the serum dilution on a colour change and the logarithmic scale.

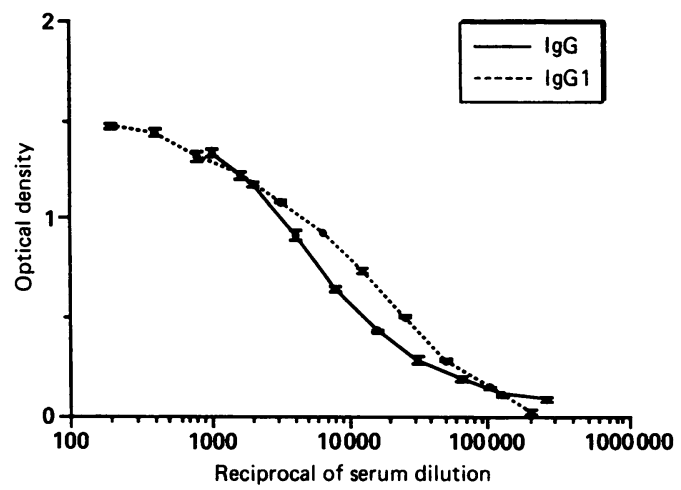

buffered saline with $0.01 \%$ Tween to remove any unbound antigen. Several dilutions of patient serum in the same buffer were then added to the wells and incubated for two hours at room temperature. The plates were again washed three times with buffer to remove unbound antibody. Horseradish peroxidase conjugated to sheep anti-human immunoglobulin (Immunodiagnostic Research Laboratory, University of Birmingham) was then added and incubated for a further two hours at room temperature. The plates were again washed to remove unbound antiglobulin, hydrogen peroxidase/o-phenylenediamine (Sigma, UK) in phosphate/citrate buffer ( $\mathrm{pH} 5.0$ ) was then added and the incubation was allowed to continue. When the colour change of a known positive standard on the plate reached a pre-determined value the reaction was stopped by the addition of $0.5 \mathrm{~mol} / 1$ citric acid. The optical density of each well was read at $490 \mathrm{~nm}$ with a spectrophotometer (Dynatech Laboratories, UK).

Assays were devised to measure total IgG, IgG1, IgG2, IgG3, IgG4, and IgM. Standard IgG and IgGl curves were generated from serum obtained from a patient who had been treated with streptokinase 10 days before (fig 1), and the IgM standard curve was generated from a known positive serum sample (kindly provided by Professor M Dykewicz, Department of Immunology, Northwestern University Medical School, Illinois, USA).

Results were expressed with reference to a fixed dilution on a standard curve that was included on every plate. This fixed titre was taken as a 1 in 6000 dilution of the standard serum for IgG and as a 1 in 4000 dilution for

Figure 2 Method of obtaining result from a patient sample. The optical density results are shown for dilutions of a patient's sample (O) and patient's sample (O) standard sample (1) obtained for the fixed dilution of the standard serum $(A)$. The point where line $B-C$ transects the patient's sample dilution curve $(D)$ is determined and the corresponding dilution $(E)$ is taken as the result for the sample.

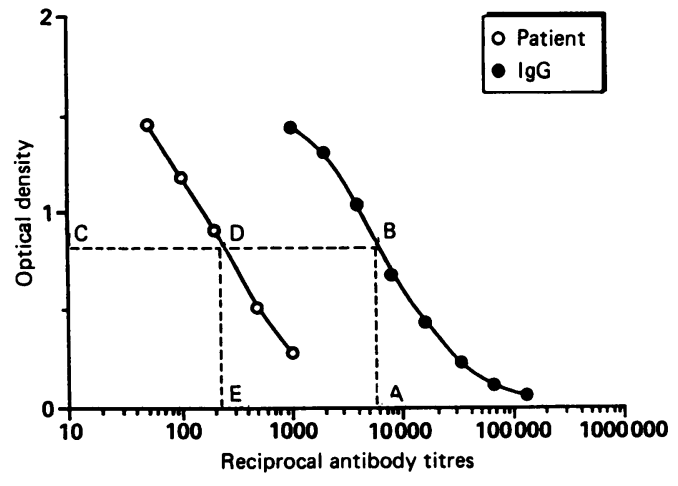

IgG1. The optical density value corresponding to the standard fixed dilution was obtained and the corresponding dilution giving the same optical density was derived from the dilution curve for each patient sample. The value obtained in this way from the patient dilution curve was taken as the result for that patient's serum. The reciprocal of the dilution was taken as the antibody titre (fig 2). Where undiluted patient serum did not achieve the optical density of the fixed standard plasma dilution the result was taken as zero for statistical purposes.

The validity of the assay was confirmed by pre-incubating pure streptokinase with positive serum in a separate experiment. When the sample was tested subsequently with the ELISAs a negative result was obtained.

The reproducibility of the assays was determined at the upper and lower ranges. For the low antibody titres we tested a patient's sample obtained before treatment. We tested within batch reproducibility by measuring the same sample six times on the same plate. At a mean IgG titre of 19 the within batch coefficient of variation (CV) was $14.7 \%$. It was $12 \cdot 7 \%$ for IgG1 (mean titre $=12$ ). Between batch reproducibility was assessed by assaying the same sample six times on different days. The between batch CV was $29 \%$ for IgG and $31.8 \%$ for IgG1.

For the high titres the reproducibility was assessed by using a patient's sample obtained 14 days after streptokinase treatment. At a mean IgG titre of 4200 the within batch CV was $6.9 \%$ and the between batch $C V$ was $12 \cdot 9 \%$. Results for IgGl (mean titre $=1750$ ) gave a within batch $\mathrm{CV}$ of $7 \cdot 7 \%$ and between batch CV of $14 \cdot 2 \%$.

Total plasma IgG and IgM were assessed by single radial immunodiffusion ${ }^{112}$ on prepoured plates (Binding Site, University of Birmingham) at presentation in the 20 patients followed after streptokinase therapy and the six patients who were not treated with streptokinase.

All results are expressed as mean (SE). The statistical significance of differences between patient groups and between daily data was determined by the Wilcoxon rank sum test for paired and unpaired data.

All patients gave informed consent and the study was approved by the local ethics committee.

\section{Results}

Twelve of the 48 patients had no detectable IgG anti-streptokinase antibody before treatment. The remaining 36 patients had titres varying from 1 to 140 . Figure 3 summarises the distribution of these titres.

Figure 4 shows the time course of the IgG response to intravenous streptokinase infusion in 20 patients. At presentation 16 of the patients had a detectable antibody titre (mean baseline titre for all 20 patients was 14.63 (4)). After infusion of streptokinase the titre showed a significant fall $(p=0.003)$ and became 
Figure 3 Distribution of baseline IgG titres of the 48 patients. The

horizontal axis indicates the reciprocal of the antibody titre. The histograms indicate the number of patients (vertical axis) with that titre. Two patients were off the scale and had baseline titres of 80 and 140 respectively.

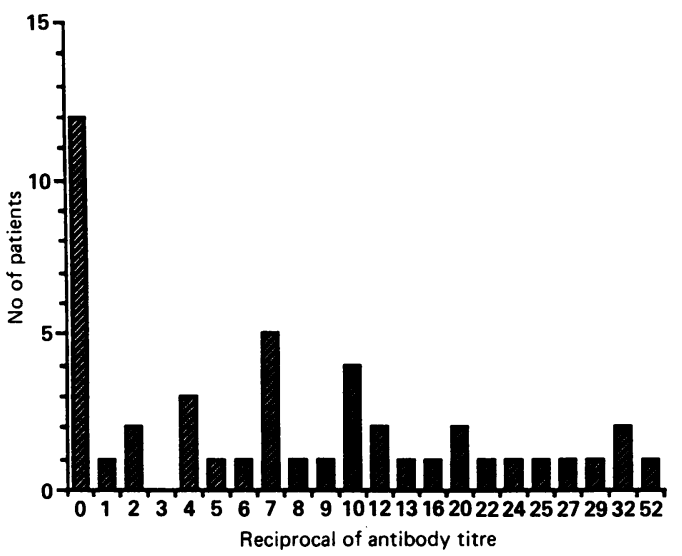

undetectable in 17 of the patients (mean titre 3 (2)). Subsequently there was a gradual increase and by day 4 the titre (91 (41)) was significantly higher than baseline concentrations $(\mathrm{p}=0.018)$. The titre increased further by day 7 reaching a peak on day 14 (mean titre 3192 (771) $(\mathrm{p}<0.0001))$. Subsequently, the titre gradually declined, levelling off after about six months. However, by one year the mean titre (131 (36)) was still higher than the baseline value $(\mathrm{p}<0.025)$.

The pattern of $I g G 1$ results resembled that for IgG. IgG1 titres were detectable in 13 patients (mean 26 (7)). Within 24 hours of treatment with streptokinase the titre decreased to $1(1.47)(p=0.003)$. Subsequently it rose and it was significantly increased by day 4 (mean $79(27)(\mathrm{p}=0.02))$. It reached a peak on day 14 (mean $1751(589)(\mathrm{p}=0.0004))$ and declined to $107(41)(\mathrm{p}<0.025)$ by one year. Figure 5 summarises the results.

There was no evidence of IgG2, IgG3, or IgG4 antibodies to streptokinase and only low titres of $\operatorname{IgM}(<1 / 30)$ which did not alter over the period of the study.

There was a large variation in the antibody response. Though the baseline titres were relatively similar for all patients, peak titres for IgG varied from 140 to 10000 , and two patients had peak titres of $<200$. However, even these patients showed no IgM antibody response to streptokinase even though total IgM and IgG were normal.

The six control patients who did not receive streptokinase had a mean baseline IgG titre of 10 (5) which was similar to that of the patients who received the drug. This titre did not

Figure 4 Time course (horizontal axis) of the IgG response (vertical axis) to intravenous streptokinase. Histograms are mean values and bars are 1 SE. All points indicated by asterisks are significantly higher than the baseline (day 0) value.

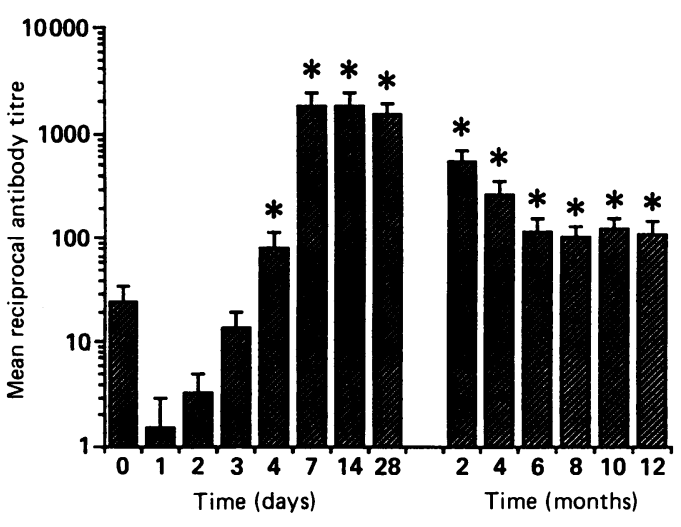

Figure 5 Time course (horizontal axis) of the IgG1 response (vertical axis) to intravenous streptokinase. Histograms are mean values and bars are 1 SE. All points indicated by asterisks are significantly higher than the baseline (day 0) values.

change in the 28 days after the infarct (day $1=$ 14 (7); day $4=11$ (6); day $14=19$ (5); day 28 $=16(5))$. Nor was there any change in IgG1 antibody titre over the same period.

Total IgG and IgM results were normal for all patients (mean total IgG concentrations = 9355 (953) $\mathrm{mg} / \mathrm{l}$; IgG range $1400-16400 \mathrm{mg} / \mathrm{l}$; mean total $\mathrm{IgM}=1739 \mathrm{mg} / \mathrm{l}(210) ; \mathrm{IgM}$ range $525-2540 \mathrm{mg} / \mathrm{l})$.

\section{Discussion}

The purpose of this study was to assess the presence and nature of streptokinase antibodies and their response to an intravenous infusion of streptokinase.

Most of the patients $(75 \%)$ had detectable IgG and IgGl antibody titres to streptokinase at presentation. The values were relatively low, but they indicate that such antibodies are widespread in the population, presumably as a result of streptococcal infection (none of our patients had been treated previously with streptokinase).

The antibody titres fell within 24 hours of treatment presumably because of combination between the antibody and antigen, streptokinase. Thereafter, the antibody titres increased gradually; they were significantly raised four days after treatment. The titres reached a peak after 14 days and subsequently declined but they had still not returned to baseline values after one year.

This pattern of immunoglobulin change suggests a secondary immune response. The antibodies found both at presentation and in the subsequent response were IgG and of the IgGl subclass as predicted for a protein antigen such as streptokinase. ${ }^{13}$ This pattern of response and the absence of a rise in IgM titre indicate that this is a secondary rather than a primary immune response. The six control patients showed no significant change in titre, again indicating that the antibody response was specific to streptokinase treatment.

Peak antibody titres to streptokinase varied considerably among patients (from 140-10 000 for IgG) with two patients showing only a slight rise (140 and 175) respectively). We do not known whether this represents an extreme 
end of the normal range or whether these two subjects have an isolated immune deficiency against protein antigens. Certainly they had no history of recurrent infections. Further studies of their response to other protein or polysaccharide antigens, however, would be needed to rule out this possibility.

The time course of the secondary immune response seen here resembles that described by Jalihal et al "for streptokinase neutralising capacity", ${ }^{14}$ indicating that the neutralisation is probably due to antibody. Jalihal et al suggested that the streptokinase dose should be titrated to overcome this neutralising capacity in patients in whom it is high. Our study suggests that if antibody is responsible for neutralisation, the dose would need to be increased if a patient presented with a second myocardial infarction within one year of the initial treatment. The administration of an increased dose of streptokinase within this period could lead to an immune reaction as well as a failure to achieve an adequate thrombolytic state. However, this possibility remains theoretical at present and further studies will be required to clarify the role and implications of these antibodies. Nevertheless, until their role has been clarified, it would be prudent to avoid repeating the dose between three days and at least one year after the initial therapy. During this period an alternative nonstreptokinase thrombolytic agent could be used.
1 ISIS (Second International Study of Infarct Survival). Collaborative Group. Randomised trial of intravenous streptokinase, oral aspirin, both or neither among 17187 cases of suspected acute myocardial infarction. Lancet 1988;ii:349-60.

2 Italian Group for the study of streptokinase in myocardial infarction (GISSI). Effectiveness of intravenous thrombolytic treatment in acute myocardial infarction. Lancet bolytic treatmen
1986;i:397-401.

3 James DCO. Anti-streptokinase levels in various hospital patient groups. Postgrad Med J 1973;(Aug suppl):26-9.

4 Fletcher AP, Alkjaersig N, Sherry S. The maintenance of a sustained thrombolytic state in man. 1. Induction and effects. J Clin Invest 1959;38:1111-9.

5 McGrath KG, Zeffren B, Alexander J, Kaplan K, Patterson $\mathrm{R}$. Allergic reactions to streptokinase consistent with anaphylactic or antigen antibody complex mediated damage. J Allergy Clin Immunol 1984;76(3):453-7.

6 Alexopoulos D, Raine AE, Cobbe SM. Serum sickness complicating intravenous streptokinase therapy in acute myocardial infarction. Eur Heart J 1984;5:1010-2.

7 Totty WG, Romano T, Benian GM, Gilula LA, Sherman LA. Serum sickness following streptokinase therapy. $A m$ J Roentgenol 1981;138:363-73.

8 Taylor C, Weatherbee TC, Esterbrooks DJ, Katz DA, Aronow WS, Kenik JG, et al Serum sickness following Aronow WS, Kenik JG, et al Serum sickness following Research 1984;35:433-8.

9 McGrath K, Patterson R. Immunology of streptokinase in human subjects. Clin Exp Immunol 1985;62:421-6.

10 Voller A, Bidwell DE, Bartlett A. Enzyme immunoassays in Voller A, Bidwell DE, Bartlett A. Enzyme immunoassays in
diagnostic medicine. Theory and practice. Bull World Health Organ 1976;76:53-65.

11 Mancini G, Carbonara AO, Heremans JF. Immunochemical quantitation of antigens by single radial immunodiffusion Immunochemistry 1965;2:235-54.

12 Fahey JL, McKelvey EM. Quantitative determination of serum immunoglobulins in antibody agar plates. Immunol 1965;94:84-90.

13 Stevens R, Dichek D, Keld B, Heiner D. IgG1 is the predominant subclass of in vivo and in vitro produced anti-tetanus toxoid antibodies and also serves as the membrane IgG molecule for delivering inhibitory signals to anti-tetanus toxoid antibody producing B cells. J Clin Immunol 1983;3(1):65-9.

14 Jalihal S, Morris GK. Antistreptokinase titres after intravenous streptokinase. Lancet 1990;335:184-5. 